\title{
Research Article \\ Effects of Deposition Time on the Morphology, Structure, and Optical Properties of PbS Thin Films Prepared by Chemical Bath Deposition
}

\author{
B. Abdallah $\mathbb{D},{ }^{1}$ A. Ismail, ${ }^{2}$ H. Kashoua, ${ }^{1}$ and W. Zetoun ${ }^{1}$ \\ ${ }^{1}$ Department of Physics, Atomic Energy Commission of Syria, P.O. Box 6091, Damascus, Syria \\ ${ }^{2}$ Department of Protection and Safety, Atomic Energy Commission of Syria, P.O. Box 6091, Damascus, Syria
}

Correspondence should be addressed to B. Abdallah; pscientific27@aec.org.sy

Received 27 November 2017; Revised 1 February 2018; Accepted 16 April 2018; Published 24 May 2018

Academic Editor: Victor M. Castaño

Copyright (c) 2018 B. Abdallah et al. This is an open access article distributed under the Creative Commons Attribution License, which permits unrestricted use, distribution, and reproduction in any medium, provided the original work is properly cited.

\begin{abstract}
Lead sulfide thin films were prepared by chemical bath deposition (CBD) on both glass and $\mathrm{Si}(100)$ substrates. XRD analysis of the $\mathrm{PbS}$ film deposited at $25^{\circ} \mathrm{C}$ showed that the prepared films have a polycrystalline structure with (200) preferential orientation. Larger grains could be obtained by increasing the deposition time. The prepared films were also chemically characterized using $\mathrm{X}$-ray photoelectron spectroscopy (XPS), which confirmed the presence of lead and sulfur as PbS. While energy dispersive X-ray spectroscopy (EDX) technique was used to verify the stoichiometry of the prepared films. Atomic force microscopy (AFM) was used to study the change in the films' morphology with the deposition time. The effect of the deposition time, on both optical transmittance in the UV-Vis-NIR region and the structure of the film, was studied. The obtained results demonstrated that the optical band gap decreased when the thickness increased.
\end{abstract}

\section{Introduction}

Lead sulfide $(\mathrm{PbS})$ has attracted great interest due to its enormous applications in the field of optoelectronics such as infrared (IR) detection [1], solar cell [2], quantum dots applications [3], and selective coating for photothermal conversion [4]. $\mathrm{PbS}$ is a semiconductor with direct narrow energy gap of $0.37-0.4 \mathrm{eV}$ at room temperature. However, this energy gap becomes higher $(1.6-2.44 \mathrm{eV})$ for nanocrystalline materials because the sizes of the crystallite become comparable to the Bohr excitonic radius, so this difference could be attributed to quantum confinement effect of $\mathrm{PbS}$ nanocrystals [5].

Also, among all other semiconductors, lead sulfide has a positive temperature coefficient of the energy gap [6]. $\mathrm{PbS}$ thin films could be prepared using different methods [7-9] such as pulsed laser ablation [10], spray pyrolysis [11], and chemical bath deposition (CBD) [12,13]. However, chemical bath deposition is mostly used $[8,14-17]$ since it is a suitable method for the deposition of polycrystalline films, at low cost and good-quality films [18]. In addition, chemical bath deposition does not require high-quality target and could be achieved without vacuum. The deposition rate and the thickness of the films are easily controlled by changing the spray deposition parameters.

In a recent work $[19,20]$, the effect of $\mathrm{ZnS}$ film thickness on its structural and electrical properties has been studied. It was demonstrated that by increasing the deposition time (thickness), the crystalline quality could be improved with developing better conducting behavior.

Due to its simplicity and versatility, the chemical bath deposition technique was used in this work to deposit $\mathrm{PbS}$ thin films on Si and glass substrates. EDX method was employed to reveal information about the composition of the films. The obtained films were then characterized by X-ray photoelectron spectroscopy (XPS) to analyze its chemical composition. XRD technique was used to study the crystallographic properties of the prepared films. The 
crystalline quality was improved, where the grain size values increased with increasing thickness. Also, the effect of the deposition time on the physical properties of the $\mathrm{PbS}$ thin films was evaluated.

\section{Experiment}

Thin polycrystalline films of $\mathrm{PbS}$ were prepared by $\mathrm{CBD}$ on both commercial glass slides and Si substrates. The substrates were washed with hot distilled water, immersed in $\mathrm{HCl}$ solution for $24 \mathrm{~h}$, and then washed with acetone. Finally, the substrates were cleaned ultrasonically with water for $20 \mathrm{~min}$. Lead acetate $\left(\mathrm{Pb}\left(\mathrm{CH}_{3} \mathrm{COO}\right)_{2}\right)$ and thiourea $\left(\mathrm{SC}\left(\mathrm{NH}_{2}\right)_{2}\right)$ were used as sources of $\mathrm{Pb}^{2+}$ and $\mathrm{S}^{2-}$ ions to form nanocrystalline $\mathrm{PbS}$ thin films. Ammonium acetate $\mathrm{NH}_{4} \mathrm{CH}_{3} \mathrm{CO}_{2}$ was used as a buffer solution to control the nucleation rate [21]. The aqueous solution of the deposition bath was prepared by the sequential addition of $5 \mathrm{ml}$ of $0.5 \mathrm{M}$ lead acetate, $5 \mathrm{ml}$ of $2.0 \mathrm{M} \mathrm{KOH}, 6 \mathrm{ml}$ of $1.0 \mathrm{M}$ thiourea, and $2 \mathrm{ml}$ of $1.0 \mathrm{M}$ triethanolamine in a $100 \mathrm{ml}$ beaker. The total volume was completed to $100 \mathrm{ml}$ with distilled water. The deposition time has been varied in the range of 10 to $120 \mathrm{~min}$. The quality of the films depends crucially on the deposition parameters, which should therefore be optimized in order to obtain highly oriented crystalline PbS films.

A scanning electron microscope (SEM) TSCAN Vega \\XMU (Czech Republic), operated at $30 \mathrm{kV}$, was used to measure the deposition time and the morphology of the prepared $\mathrm{PbS}$ films.

Atomic composition and stoichiometry of the $\mathrm{PbS}$ films were determined by EDX. The chemical composition of the films has been determined using the X-ray photoelectron technique. The XPS analyses were performed using a SPECS UHV/XPS/AES system with a hemispherical energy analyzer. The monochromated $\mathrm{Al} \mathrm{K} \alpha \mathrm{X}$-ray source $(1486.6 \mathrm{eV})$ is used as the excitation source and is operated at $250 \mathrm{~W}$ [22]. In addition, X-ray diffraction (XRD) STOE transmission Xray diffractometer (Stadi $\mathrm{P}$ ) (Germany) was used to analyze the crystallographic properties of the prepared films, and low-energy electrons issued from a flood gun were used to compensate for the charging effect. The XRD analysis was realized by using the $\mathrm{Cu} K \alpha(\lambda=0.15405 \mathrm{~nm})$ radiation in a linear position sensitive detector for $\theta-2 \theta$ scan configuration. The morphology of the prepared $\mathrm{PbS}$ films was also analyzed using AFM (Park Scientific Instruments AP-0100 model) with the noncontact mode. The mean grain size, grain distribution, and surface roughness were determined using the WSxm software. In addition, the optical characteristics were examined by measuring the transmittance of the prepared films using a UV-Vis Shimadzu UV-310PC spectrophotometer. The experimental set-up consists of $\mathrm{UV}$ excitation using a $325 \mathrm{~nm} \mathrm{He} / \mathrm{Cd}$ laser and grating monochromator (1200 groves $/ \mathrm{mm}$ ) equipped with a cooled photomultiplier tube PMT. Two types of substrates were used for different methods of analysis. EDX analysis is better performed for films on silicon substrate, while a UV transmission study requires films deposited on transparent materials in the visible region such as glass substrate.

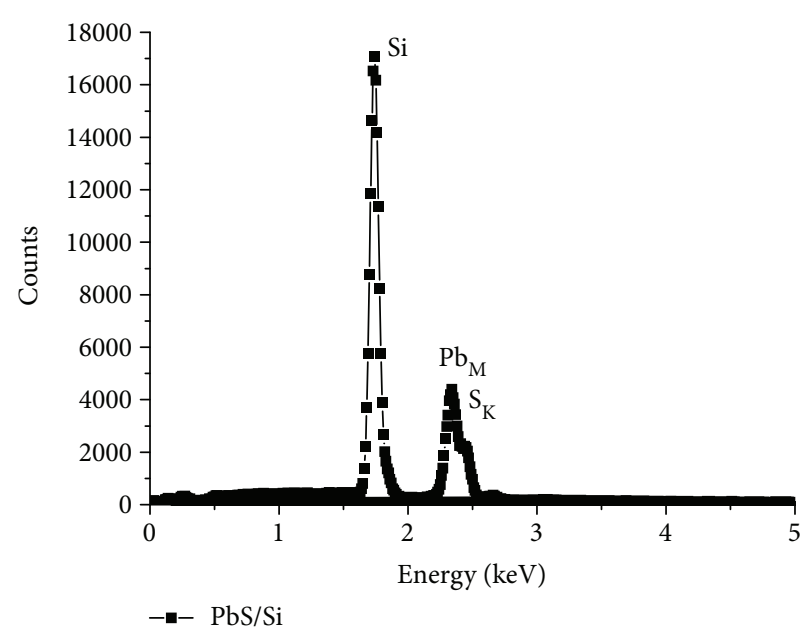

Figure 1: EDX spectrum for PbS film deposited on Si substrate for a deposition time of $30 \mathrm{~min}$.

\section{Results and Discussion}

\subsection{Composition Study}

3.1.1. EDX Study. The EDX analysis shows the prepared film composed of $\mathrm{Pb}$ and $\mathrm{S}$ atoms as illustrated in Figure 1.

The atomic ratio of the sulfide $\mathrm{S}$ in the sample is higher than that of lead $(\mathrm{Pb}):(\mathrm{S} / \mathrm{Pb}=48.62 \% / 51.38 \%=0.94)$. The spectrum indicates that oxygen contamination is less than $1 \%$. The peak indicates the presence of $\mathrm{Si}$, which arises from the substrate.

The obtained results show the stoichiometry of the prepared PbS films.

3.1.2. XPS Study. Figure 2 presents the XPS spectra of PbS film obtained at $30 \mathrm{~min}$. It could be noted that the prepared films are principally consisted of lead and sulfur corresponding to the formation of PbS. However, the $\mathrm{O}$ 1s core level peak, which is located at $531.75 \mathrm{eV}$, corresponding to oxygen, and the $\mathrm{C}$ 1s core level peak related to adventitious carbon were noted. In addition, a high percentage of lead hydroxide in the surface of the films was found. This was explained as the lead hydroxide could be an intermediary compound according to $\mathrm{PbS}$ reaction mechanism [23]. In addition, Figure 2 shows in detail the $\mathrm{Pb} 4 \mathrm{f}$ doublet of prepared film. The position of the $\mathrm{Pb} 4 \mathrm{f} 7 / 2$ of $137.5 \mathrm{eV}$ is in good agreement with reported values in literature for $\mathrm{PbS}[23,24]$. The $\mathrm{S} 2 \mathrm{p}$ core peaks for both films are located at $160.75 \mathrm{eV}$, which corresponds to sulfur as $\mathrm{PbS}$ [25-27]. Bonding energy for $\mathrm{S}$ $2 \mathrm{p} 3 / 2$ at $161 \mathrm{eV}$ is indicative of a metal sulfide, $\mathrm{PbS}$ in this case [28]. These results are analogous to the reported values of $\mathrm{PbS}$ nanoparticles [29].

The peaks at $\sim 225.5 \mathrm{eV}$ (Figure 2(b)) is corresponding to S 2s. Reiche et al. [30] found that the S 2s (225.4-225.8 eV) peak shifts are size related, and the higher oxygen amount is bonded to the $\mathrm{Pb}$ but not to the $\mathrm{S}$ atoms.

The peak at $142.0 \mathrm{eV}$ (Figure 2(c)) is assigned to the binding energies of $\mathrm{Pb} 4 \mathrm{f5} / 2$, which is in good accordance with data obtained in literature [31]. 


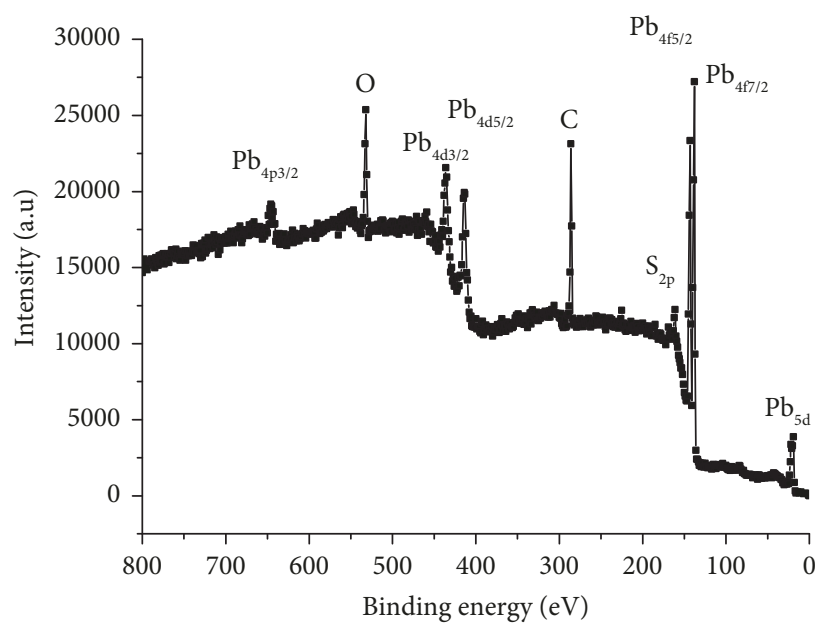

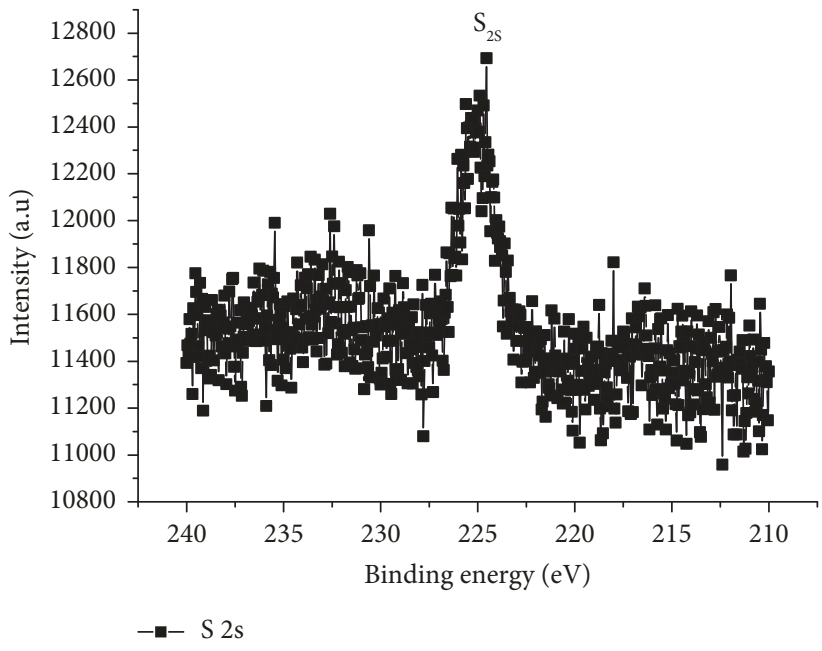

(b)

(a)

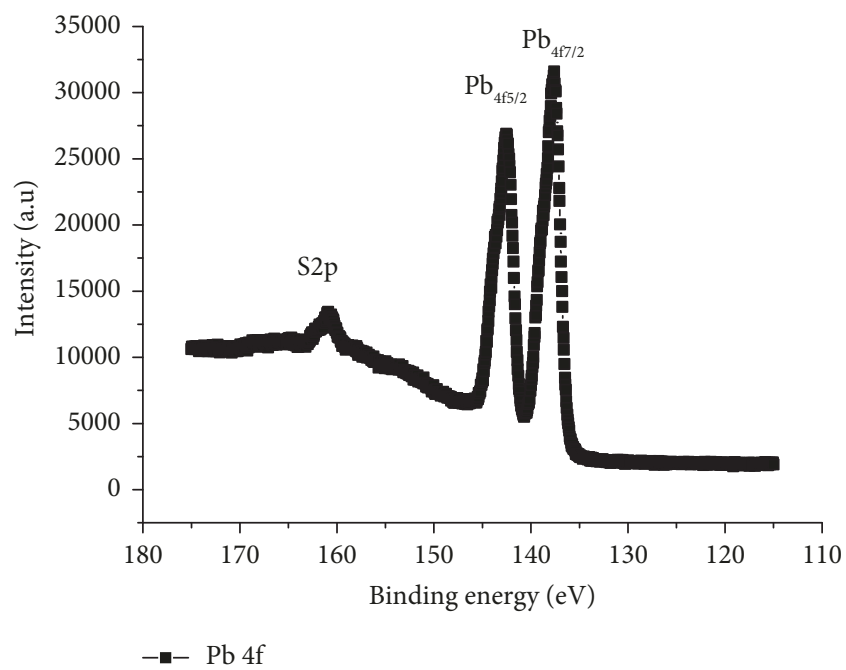

(c)

FIGURE 2: (a) XPS survey scan for PbS deposited at $30 \mathrm{~min}$ and (b and c) XPS high-resolution spectra for sample prepared S 2s and for Pb, respectively.

3.2. XRD Study. Figure 3 shows XRD pattern of PbS films deposited for different times, and all reflected peaks with (200) preferential orientation can be indexed to the cubic structure of $\mathrm{PbS}$ with lattice parameters $a=0.59143 \mathrm{~nm}$, and it shows that small peaks (111), (220) (311), and (222) correspond to $26.10^{\circ}, 43.22^{\circ}, 51.20^{\circ}$, and $53.62^{\circ}$, respectively, in good agreement with the PDF database (number $78^{-}$ 1054). The two small peaks at $34.1^{\circ}$ and $47.5^{\circ}$ are due to the stainless steel 304 holder. It has been observed that the intensity of the peaks increased and the crystallization of $\mathrm{PbS}$ thin films were improved with increasing film thickness, similar to other reports [12].

The intensity of the XRD (200) peak gets stronger with deposition time indicating the increase of the film thickness as shown in Figure 3(a). Grain size has been deduced from XRD pattern using Scherrer's formula [32] for (111), (200) (220), and (311) orientations. It was found that the crystallite size increases with increasing the thickness (Figure 3(b)).
The grain size for the (111) peak increased from $10 \mathrm{~nm}$ to $27 \mathrm{~nm}$ with increasing thickness, whereas the grain size for the (200) peak increased from $26 \mathrm{~nm}$ to $47 \mathrm{~nm}$. This behavior is in agreement with other studies [11]. This means that the thicker films have less defect concentrations (bigger grain size and fine grain boundary). The behavior of increasing the resistivity with average grain size agrees with other reported work [33] but does not agree with other studies of ZnS film deposited by ultrasonic spray pyrolysis [19, 20]. The increase in the film thickness leads to an improvement of the crystalline quality. This is attributed to the strain in the film introduced during the deposition [34], that is, the thicker films suffer less strain than the thinner ones. This comes in a good agreement with our results where thicker films have lower stress value and better quality.

3.3. SEM and AFM Study. This kind of texture and growth was found in all samples under investigation and confirmed the analysis already presented. The morphology of 


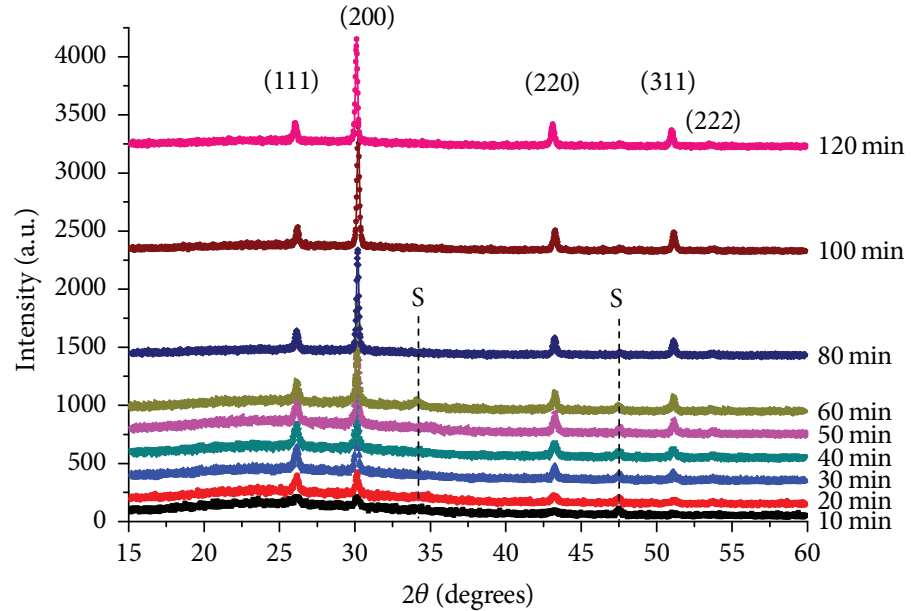

(a)

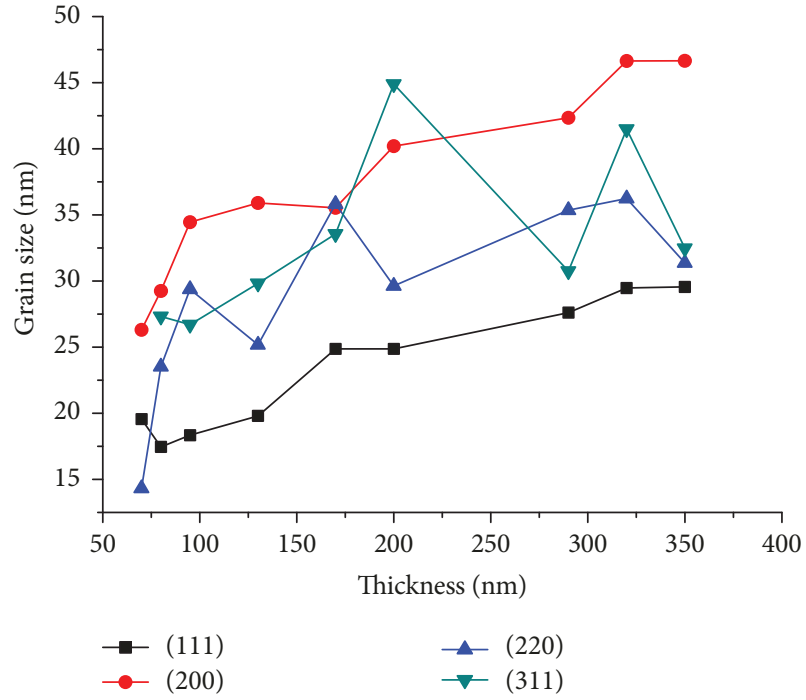

(b)

FIGURE 3: (a) XRD pattern of PbS thin film and (b) grain size evolution with film thickness deposited on glass substrate for different times.

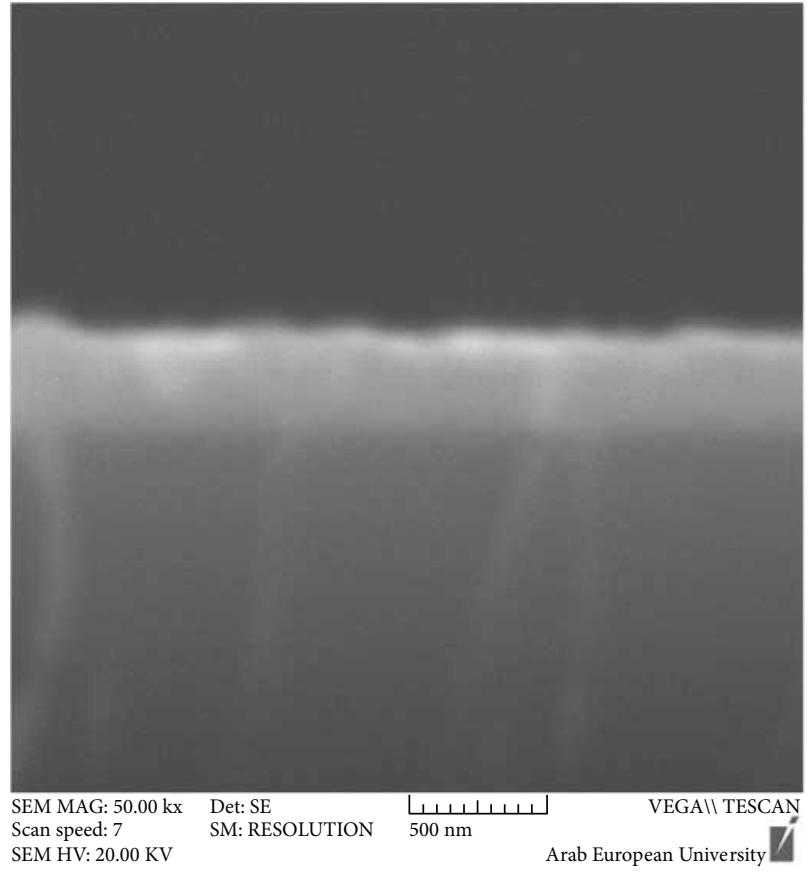

(a)

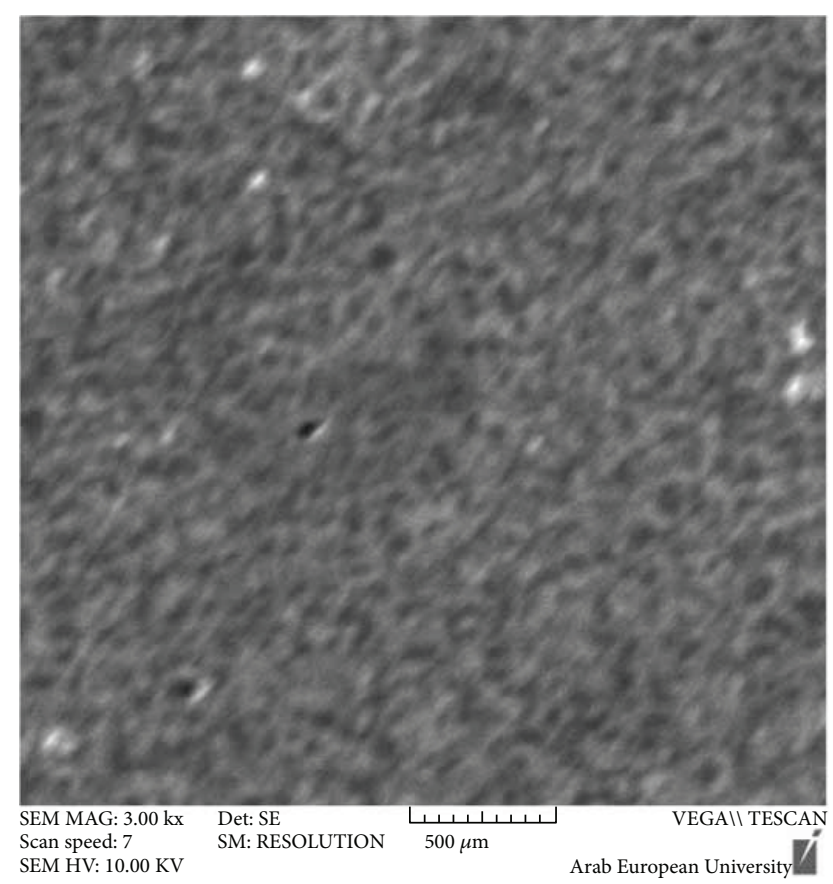

(b)

FIgURE 4: Typical SEM micrographs of PbS/Si thin films deposited for $100 \mathrm{~min}$ : (a) cross-sectional view and (b) surface view.

the films deposited at a certain time depends mainly on the deposition rate, $\mathrm{pH}$, concentration, and speed of the substrate rotation [35].

The cross-section of PbS thin film deposited for $100 \mathrm{~min}$ is shown in Figure 4(a) where the thickness was about $320 \mathrm{~nm}$. The surface morphology is shown in Figure 4(b).

The AFM surface topography of as-deposited $\mathrm{PbS}$ film at time $10 \mathrm{~min}$ (Figures 5(a) and 5(b)) shows a nanostructured surface with well-defined grains of mean size $=13 \mathrm{~nm}$. The surfaces of the products of $\mathrm{PbS}$ thin films were obviously smooth. The AFM surface topography (Figures 5(c) and 5(d)) changes for thicker film deposited at $100 \mathrm{~min}$ (corresponding thickness: $320 \mathrm{~nm}$ ).

The roughness of the prepared films, expressed as root mean square (RMS) roughness was obtained from AFM measurements, and their evolutions with deposition time are increased by increasing the thickness, where it varied from $2 \mathrm{~nm}$ (at $70 \mathrm{~nm}$ thickness) to a maximum value of 


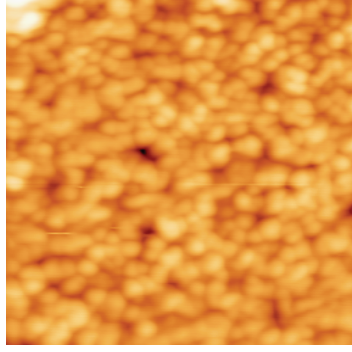

$10 \min (70 \mathrm{~nm})$

(a)

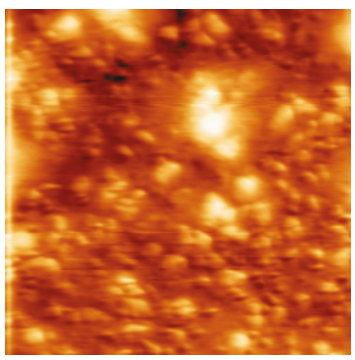

$100 \min (320 \mathrm{~nm})$

(c)

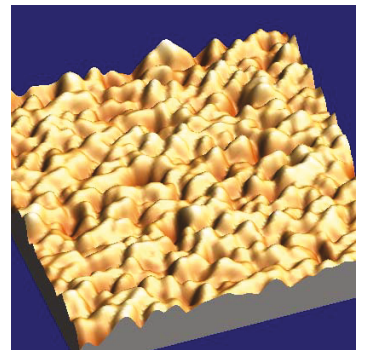

$10 \min (70 \mathrm{~nm})$

(b)

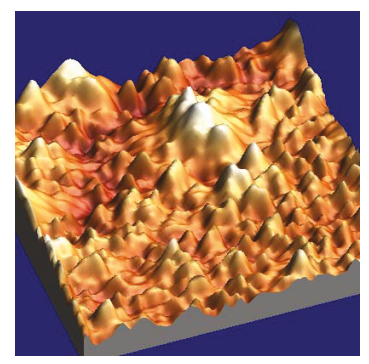

$100 \min (320 \mathrm{~nm})$

(d)

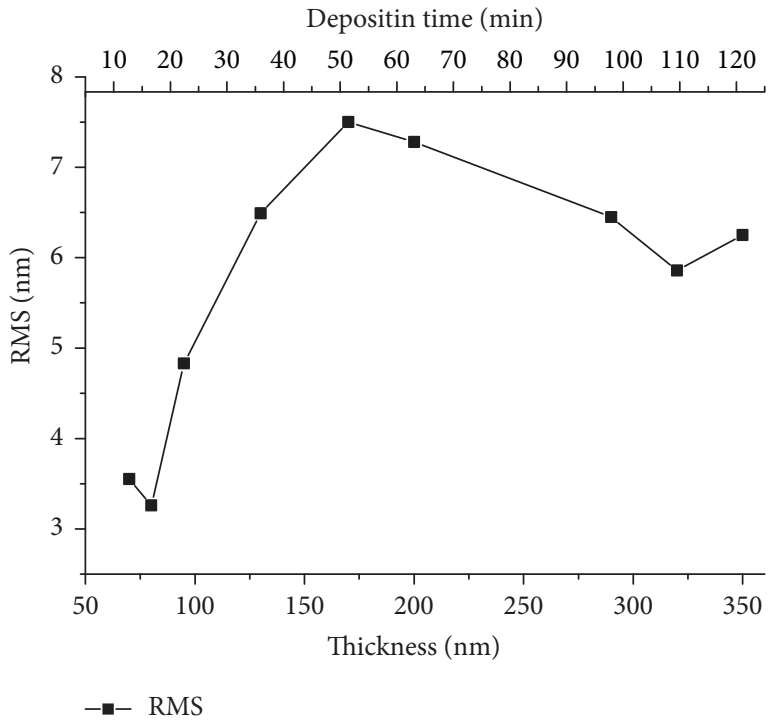

(e)

Figure 5: AFM images films (a) 2D and (b) 3D for deposition time of $10 \mathrm{~min}$, (c) 2D and (d) 3D at 100 min, and (e) RMS evolution with time for $\mathrm{CBD} \mathrm{PbS}$ film on glass substrate.

$7 \mathrm{~nm}$ (at $170 \mathrm{~nm}$ thickness). After that, it decreases to about $6 \mathrm{~nm}$ for thicker films (350 $\mathrm{nm}$ thickness) as shown in Figure 5(e). The obtained results agree with Kakhia et al. [36]. The increase of RMS roughness with the increase of film thickness was due to the larger grain formation as well as increase in the porosity [37]. In our case, the film deposited by CBD showed lower roughness than the film prepared by spray pyrolysis method [11]. According to Pérez-García et al. [38], the thickness increases with the deposition time from 58 to $200 \mathrm{~nm}$ and the roughness increases from $3.5 \mathrm{~nm}$ to $14 \mathrm{~nm}$ for the PbS films grown by CBD.

3.4. Optical Properties. Figure 6 shows the UV-Vis-NIR transmission spectra for films (from $10 \mathrm{~nm}$ to $200 \mathrm{~nm}$ ). It has been observed that the average transmittance of the studied samples in the visible range decreased from $40 \%$ to $20 \%$ with increased film thickness. The optical transmittance provides useful information about the optical band gap of the semiconductor [34] as shown in Figure 6.

The obtained values of the optical band gap for different thicknesses are shown in Figure 7(a). The plots of $(\alpha h v)^{2}$ as a function of $h v$ are shown in Figure 7 (a) in accordance with (1), which is valid for energies $h v$ not exceedingly high, where $A$ is a constant, $h v$ is the photon energy, $E_{\mathrm{g}}$ is the band gap, and $p$ is 0.5 .

$$
\alpha=A\left(h v-E_{\mathrm{g}}\right)^{p} .
$$

Figure 7(b) shows that the optical band gap decreases slightly from $2.75 \pm 0.02 \mathrm{eV}$ to $2.29 \pm 0.02 \mathrm{eV}$ with the thickness increasing from $70 \mathrm{~nm}$ to $200 \mathrm{~nm}$, which indicates that the band gap value is, to some extent, influenced by the sample thickness. However, this influence is not sufficiently

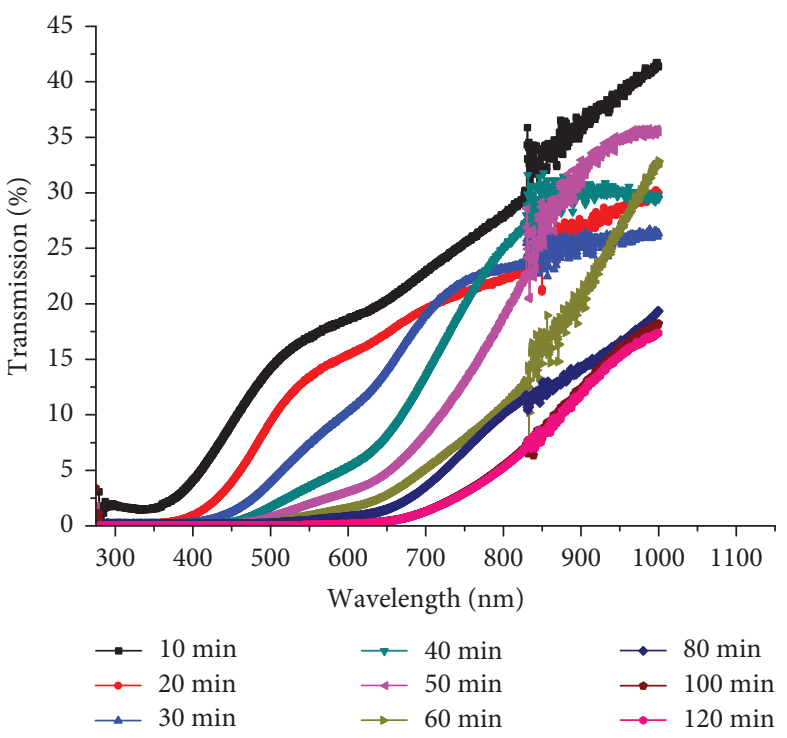

FIgURE 6: The transmittance spectra for films deposited on glass substrate for different times.

important. The $E_{\mathrm{g}}$ values decreases with increasing thicknesses, and this is attributed to the increases of density of localized state in the energy gap. These values of $E_{\mathrm{g}}$ are in good agreement with those published by $[39,40]$. It is reported that the size effect on the optical $E_{\mathrm{g}}$ is stronger for the NC films than for PbS nanocrystals with average crystallite size of $24-10 \mathrm{~nm}$, showing $E_{\mathrm{g}}$ varying from 2.22 to $2.65 \mathrm{eV}$ [41]. Ezugwu et al. [5] explain the reason for the difference between the energy gap values for PbS bulk and nanocrystalline. 


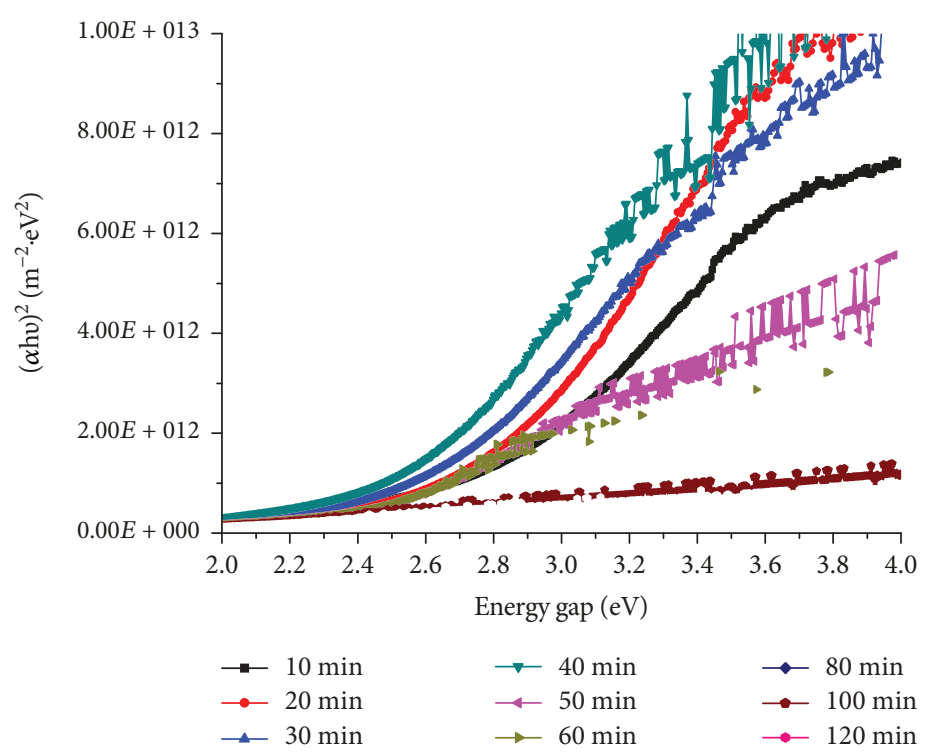

(a)

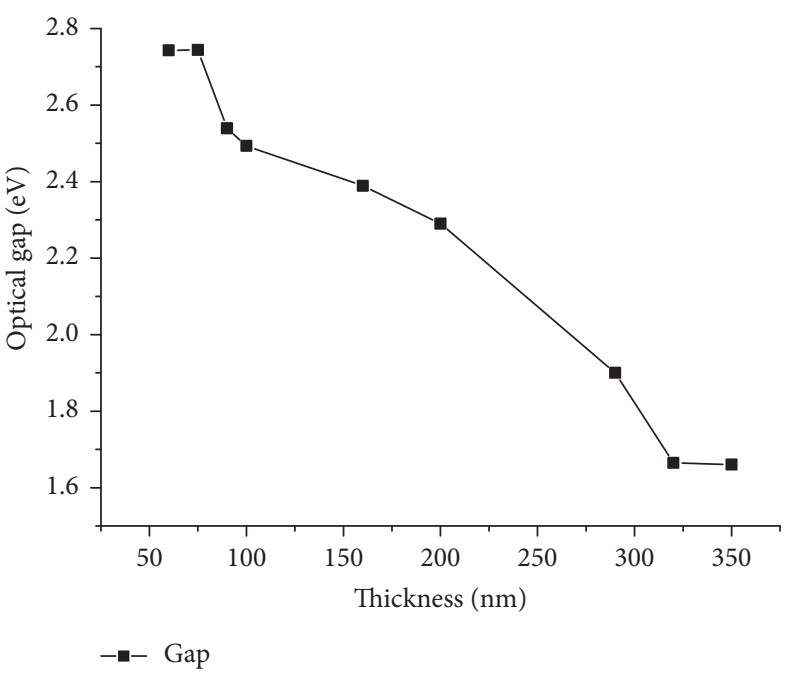

(b)

Figure 7: (a) Optical band gap of PbS film and (b) corresponding value evolution with the thickness.

The optical band gap decreases sharply from 2.29 to $1.66 \mathrm{eV}$ where thickness increases to $350 \mathrm{~nm}$ (Figure 7(b)). Abbas et al. [12] have studied and shown that PbS thin films have allowed direct transition and the values of energy gap varied between 1.88 and $1.55 \mathrm{eV}$ with increasing the film thickness $(500-660 \mathrm{~nm})$. Beddek et al. [13] found that $E_{\mathrm{g}}$ decreased with increasing bath $\mathrm{pH}$, certainly due to the increase of crystallite size; the same behavior has been observed in many studies. This behavior agrees with reported studies [21, 42]. This could be explained by the improvement of the crystalline quality (grain size with thickness) [19, 43].

\section{Conclusion}

In this work, $\mathrm{PbS}$ thin films were grown on glass and $\mathrm{Si}$ substrates by CBD and the effects of growth conditions such as the deposition time of the constituents on structural and optical properties were studied.

The $\mathrm{PbS}$ thin films have cubic phase and preferred orientation in the (200) plane. XRD spectra indicate that there is no stress in the films. The grain sizes are estimated to be in the range of $25-47 \mathrm{~nm}$ wherein the time evaluated was from 10 to $120 \mathrm{~min}$. The crystalline quality (grain size) improves with increasing thickness. Film thickness ranged from $70 \mathrm{~nm}$ to $350 \mathrm{~nm}$, depending on the growth conditions. XPS analyses showed that the chemical bath deposition technique is clean because there are no contaminants and confirm that the main components of this thin film are lead and sulfur. From AFM images, it was found that the RMS roughness of the film surface increased as the film thickness increased. Optical band gap and refractive indices values have been deduced from UV spectra for films deposited on glass substrates, and the energy gap was decreased slightly from $2.75 \mathrm{eV}$ to $2.29 \mathrm{eV}$; after that, it decreased to $1.66 \mathrm{eV}$ for the maximum thickness $(350 \mathrm{~nm})$.

\section{Conflicts of Interest}

The authors declare that they have no conflicts of interest.

\section{Acknowledgments}

The authors greatly acknowledge funds to this project by Professor I. Othman, the director general of the Atomic Energy Commission of Syria. Moreover, the authors would like to thank Professor M. S. Al-Masri for his continuous support.

\section{References}

[1] M. S. Ghamsari, M. K. Araghi, and S. J. Farahani, “The influence of hydrazine hydrate on the photoconductivity of $\mathrm{PbS}$ thin film," Materials Science and Engineering: B, vol. 133, no. 1-3, pp. 113-116, 2006.

[2] S. Günes, K. P. Fritz, H. Neugebauer, N. S. Sariciftci, S. Kumar, and G. D. Scholes, "Hybrid solar cells using PbS nanoparticles," Solar Energy Materials and Solar Cells, vol. 91, no. 5, pp. 420-423, 2007.

[3] A. M. Malyarevich, M. S. Gaponenko, V. G. Savitski, K. V. Yumashev, G. E. Rachkovskaya, and G. B. Zakharevich, "Nonlinear optical properties of $\mathrm{PbS}$ quantum dots in boro-silicate glass," Journal of Non-Crystalline Solids, vol. 353, no. 11-12, pp. 1195-1200, 2007.

[4] T. K. Chaudhur, "A solar thermophotovoltaic converter using PbS photovoltaic cells," International Journal of Energy Research, vol. 16, no. 6, pp. 481-487, 1992.

[5] S. C. Ezugwu, F. I. Ezema, R. U. Osuji et al., "Optical studies of chemically deposited PVA-capped PbS nanoparticle thin films," Optoelectronics and advanced materials-rapid Communications, vol. 3, no. 6, pp. 528-532, 2009.

[6] R. K. Das, S. Sahoo, and G. S. Tripathi, "Electronic structure of high density carrier states in PbS, PbSe and PbTe," Semiconductor Science and Technology, vol. 19, no. 3, pp. 433-441, 2004. 
[7] C. Li, G. Shi, H. Xu, S. Guang, R. Yin, and Y. Song, "Nonlinear optical properties of the PbS nanorods synthesized via surfactant-assisted hydrolysis," Materials Letters, vol. 61, no. 8-9, pp. 1809-1811, 2007.

[8] I. Pop, C. Nascu, V. Ionescu, E. Indrea, and I. Bratu, "Structural and optical properties of PbS thin films obtained by chemical deposition," Thin Solid Films, vol. 307, no. 1-2, pp. 240-244, 1997.

[9] A. B. Preobrajenski and T. Chassé, "Epitaxial growth and interface structure of $\mathrm{PbS}$ on $\operatorname{InP}(110), "$ Applied Surface Science, vol. 142, no. 1-4, pp. 394-399, 1999.

[10] Y. Z. Dawood, S. M. Kadhim, and A. Z. Mohammed, "Structure and optical properties of nano $\mathrm{PbS}$ thin film deposited by pulse laser deposition," Eng \& Tech Journal,. Part (B), vol. 32, pp. 1723-1730, 2015.

[11] M. G. Faraj, "Effect of thickness on the structural and electrical properties of spray pyrolysed lead sulfide thin films," American journal of condensed matter Physics, vol. 5, no. 2, pp. 51-55, 2015.

[12] M. M. Abbas, A. A.-M. Shehab, A. K. Al-Samuraee, and N. A. Hassan, "Effect of deposition time on the optical characteristics of chemically deposited nanostructure PbS thin films," Energy Procedia, vol. 6, pp. 241-250, 2011.

[13] L. Beddek, M. Messaoudi, S. Guitouni, N. Attaf, and M. S. Aida, "Determination of heterojunction band offsets between $\mathrm{CdS}$ bulk and $\mathrm{PbS}$ quantum dots using photoelectron spectroscopy," International Journal of Scientific Research \& Engineering Technology, vol. 3, pp. 138-142, 2015.

[14] R. A. Orozco-Terán, M. Sotelo-Lerma, R. Ramirez-Bon, M. A. Quevedo-López, O. Mendoza-González, and O. Zelava-Angel, "PbS-CdS bilayers prepared by the chemical bath deposition technique at different reaction temperatures," Thin Solid Films, vol. 343-344, pp. 587-590, 1999.

[15] E. Pentia, L. Pintilie, I. Matei, T. Botila, and E. Ozbay, "Chemically prepared nanocrystalline PbS thin films," Journal of Optoelectronics and Advanced Materials, vol. 3, no. 2, pp. 525-530, 2001.

[16] J. J. Valenzuela-Jáuregui, R. Ramírez-Bon, A. MendozaGalván, and M. Sotelo-Lerma, "Optical properties of $\mathrm{PbS}$ thin films chemically deposited at different temperatures," Thin Solid Films, vol. 441, no. 1-2, pp. 104-110, 2003.

[17] H. Zhang, X. Ma, J. Xu, and D. Yang, "Synthesis of CdS nanotubes by chemical bath deposition," Journal of Crystal Growth, vol. 263, no. 1-4, pp. 372-376, 2004.

[18] C. D. Lokhande, "Chemical deposition of metal chalcogenide thin films," Materials Chemistry and Physics, vol. 27, no. 1, pp. 1-43, 1991.

[19] B. Abdallah, A. K. Jazmatia, and R. Refaai, "Oxygen effect on structural and optical properties of $\mathrm{ZnO}$ thin films deposited by RF magnetron sputtering," Materials Research Innovations, vol. 20, no. 3, pp. 607-612, 2017.

[20] K. Alnama, B. Abdallah, and S. Kanaan, "Deposition of ZnS thin film by ultrasonic spray pyrolysis: effect of thickness on the crystallographic and electrical properties," Composite Interfaces, vol. 24, no. 5, pp. 499-513, 2017.

[21] A. S. Obaid, M. A. Mahdi, A. Ramizy, and Z. Hassan, "Growth of nanocrystalline $\mathrm{PbS}$ thin films by solid-vapor deposition," Advanced Materials Research, vol. 364, pp. 60-64, 2012.

[22] O. Mrad, I. M. Ismail, B. Abdallah, and M. Rihawy, "Optical and chemical properties of vanadium oxide thin films prepared by vacuum arc discharge," Journal of Optoelectronics and Advanced Materials, vol. 16, pp. 1099-1103, 2014.
[23] J. O. Rivera-Nieblas, J. Alvarado-Rivera, M. C. AcostaEnríquez et al., "Resistance and resistivities of $\mathrm{PbS}$ thin films using polyethylenimine by chemical bath deposition," Chalcogenide Letters, vol. 10, no. 9, pp. 349-358, 2013.

[24] K. P. Bhandari, H. Choi, S. Jeong, H. Mahabaduge, and R. J. Ellingson, "Determination of heterojunction band offsets between $\mathrm{CdS}$ bulk and $\mathrm{PbS}$ quantum dots using photoelectron spectroscopy," Applied Physics Letters, vol. 105, no. 13, article 131604, 2014.

[25] C. Huaqiang, W. Guozhi, Z. Sichun, and Z. Xinrong, "Growth and photoluminescence properties of $\mathrm{PbS}$ nanocubes," Nanotechnology, vol. 17, no. 13, article 3280, 2006.

[26] A. Kar, S. Sain, D. Rossouw, B. R. Knappett, S. K. Pradhan, and A. E. H. Wheatley, "Facile synthesis of $\mathrm{SnO}_{2}-\mathrm{PbS}$ nanocomposites with controlled structure for applications in photocatalysis," Nanoscale, vol. 8, no. 5, pp. 2727-2739, 2016.

[27] Y. Ramin, C. Mohsen, J.-S. Farid, M. R. Mahmoudian, S. Abdolhossein, and H. Nay Ming, "Influences of anionic and cationic dopants on the morphology and optical properties of PbS nanostructures," Chinese Physics B, vol. 23, no. 10, article 108101, 2014.

[28] X.-R. Yu, F. Liu, Z.-Y. Wang, and Y. Chen, “Auger parameters for sulfur-containing compounds using a mixed aluminumsilver excitation source," Journal of Electron Spectroscopy and Related Phenomena, vol. 50, no. 2, pp. 159-166, 1990.

[29] P. S. Khiew, S. Radiman, N. M. Huang, and M. S. Ahmad, "Studies on the growth and characterization of $\mathrm{CdS}$ and $\mathrm{PbS}$ nanoparticles using sugar-ester nonionic water-in-oil microemulsion," Journal of Crystal Growth, vol. 254, no. 1-2, pp. 235-243, 2003.

[30] R. Reichea, R. Thielschb, S. Oswalda, and K. Wetziga, "XPS studies and factor analysis of $\mathrm{PbS}$ nanocrystal-doped $\mathrm{SiO}_{2}$ thin films," Journal of Electron Spectroscopy and Related Phenomena, vol. 104, no. 1-3, pp. 161-171, 1999.

[31] M. Takahashi, Y. Ohshima, K. Nagata, and S. Furuta, "Electrodeposition of PbS films from acidic solution," Journal of Electroanalytical Chemistry, vol. 359, no. 1-2, pp. 281-286, 1993.

[32] P. Scherrer, "Bestimmung der Grosse und der Inneren Struktur von Kolloidteilchen Mittels Rontgenstrahlen, Nachrichten von der Gesellschaft der Wissenschaften, Gottingen," Mathematisch-Physikalische Klasse, vol. 2, pp. 98-100, 1918.

[33] T. David, S. Goldsmith, and R. L. Boxman, "Dependence of zinc oxide thin film properties on filtered vacuum arc deposition parameters," Journal of Physics D: Applied Physics, vol. 38, no. 14, pp. 2407-2416, 2005.

[34] B. Abdallah and S. Al-Khawaja, "Optical and electrical characterization of (002)-preferentially oriented $\mathrm{n}-\mathrm{ZnO} / \mathrm{p}-\mathrm{Si}$ heterostructure," Acta Physica Polonica, vol. 128, no. 2, pp. 283-289, 2015.

[35] M. A. Barote, A. A. Yadav, and E. U. Masumdar, "Effect of deposition parameters on growth and characterization of chemically deposited $\mathrm{Cd}_{1-\mathrm{X}} \mathrm{Pb}_{\mathrm{X}} \mathrm{S}$ thin films," Chalcogenide Letters, vol. 8, no. 2, pp. 129-138, 2011.

[36] M. Kakhia, B. Abdallah, and S. Abou Shaker, "Deposition of $\mathrm{Na}_{2} \mathrm{WO}_{4}$ films by ultrasonic spray pyrolysis: effect of thickness on the crystallographic and sensing properties," Composite Interfaces, vol. 23, no. 7, pp. 663-674, 2016.

[37] N. Kakati, S. H. Jee, S. H. Kim, J. Y. Oh, and Y. S. Yoon, "Thickness dependency of sol-gel derived $\mathrm{ZnO}$ thin films on gas sensing behaviors," Thin Solid Films, vol. 519, no. 1, pp. 494-498, 2010. 
[38] C. E. Pérez-García, R. Ramírez-Bon, and Y. V. Vorobiev, "PbS thin films growth with CBD and PCBD techniques: a comparative study," Chalcogenide Letters, vol. 12, no. 11, pp. 579-588, 2015.

[39] R. K. Joshi, A. Kanjilal, and H. Sehgal, "Solution grown PbS nanoparticle films," Applied Surface Science, vol. 221, no. 1-4, pp. 43-47, 2004.

[40] A. U. Ubale, A. R. Junchara, N. H. Wadibhasme, A. S. D. Purkab, R. B. Mankar, and V. S. Sangawar, "Thickness dependent structural, electrical and optical properties of chemically deposited nanopartical PbS thin films," Turkish Journal of Physics, vol. 31, pp. 279-286, 2007.

[41] Z. Bo, L. Guanghai, Z. Jun, Z. Yong, and Z. Lide, "Synthesis and characterization of $\mathrm{PbS}$ nanocrystals in water/ $\mathrm{C}_{12} \mathrm{E}_{9} /$ cyclohexane microemulsions," Nanotechnology, vol. 14, no. 4 , pp. 443-446, 2003.

[42] T. C. Chi, "Structure, morphology, and optical properties of the compact, vertically-aligned $\mathrm{ZnO}$ nanorod thin films by the solution-growth technique," in Nanorods InTech, O. Yalçın, Ed., p. 33, InTech, Croatia, 2012.

[43] S. Al-Khawaja, B. Abdallah, S. Abou Shaker, and M. Kakhia, "Thickness effect on stress, structural, electrical and sensing properties of $\left(\begin{array}{lll}0 & 0 & 2\end{array}\right)$ preferentially oriented undoped $\mathrm{ZnO}$ thin films," Composite Interfaces, vol. 22, no. 3, pp. 221-231, 2015. 


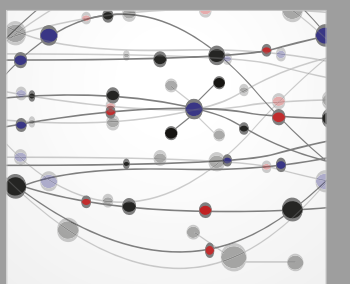

The Scientific World Journal
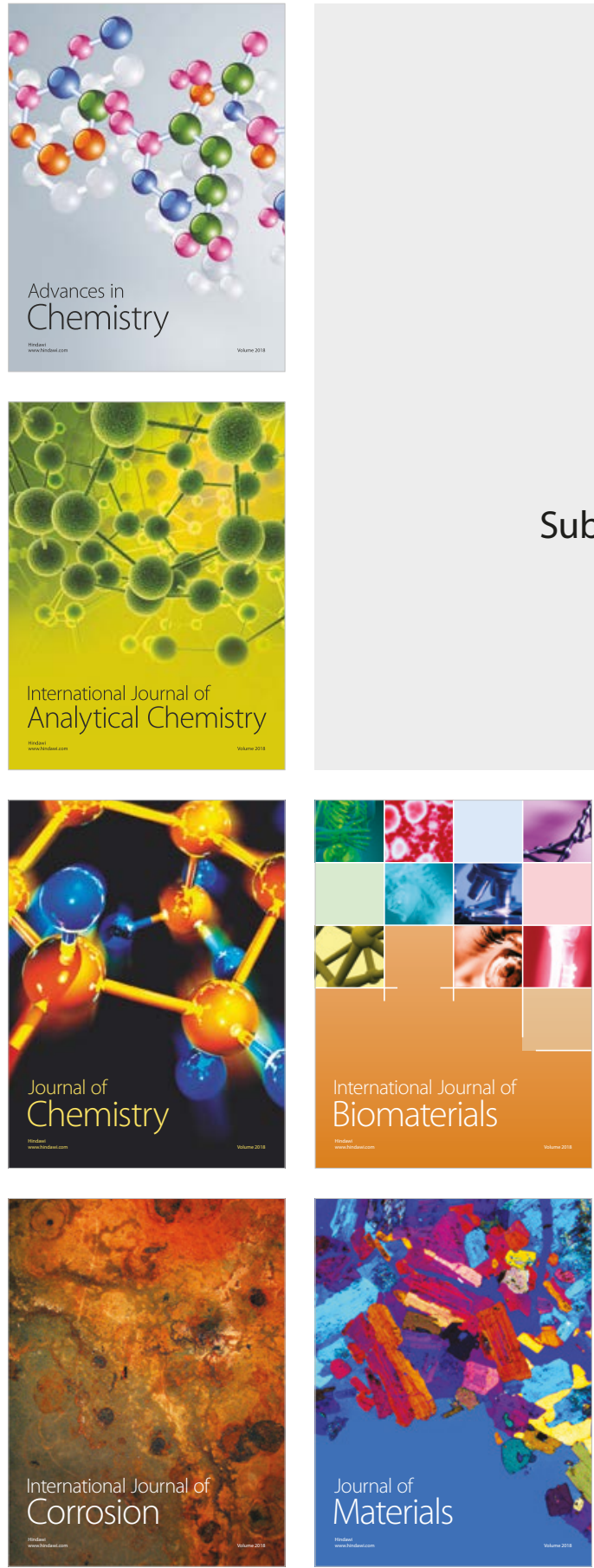

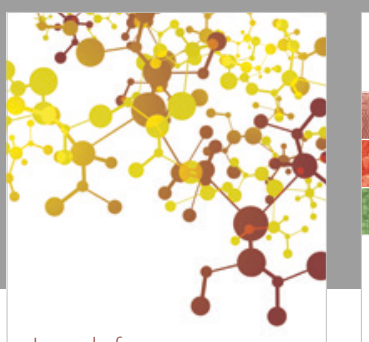

Journal of

Applied Chemistry
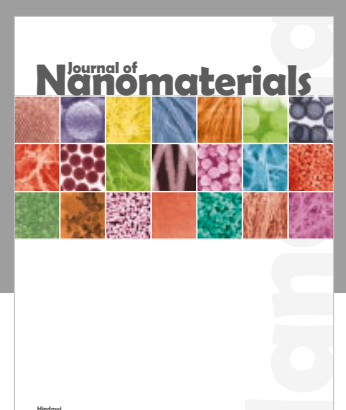

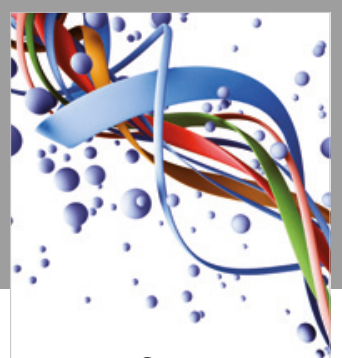

Scientifica

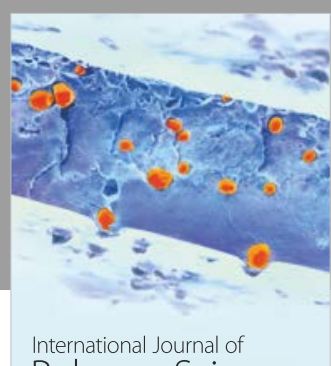

Polymer Science

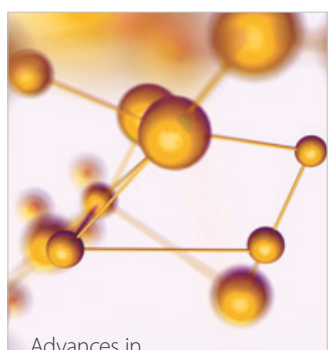

Physical Chemistry
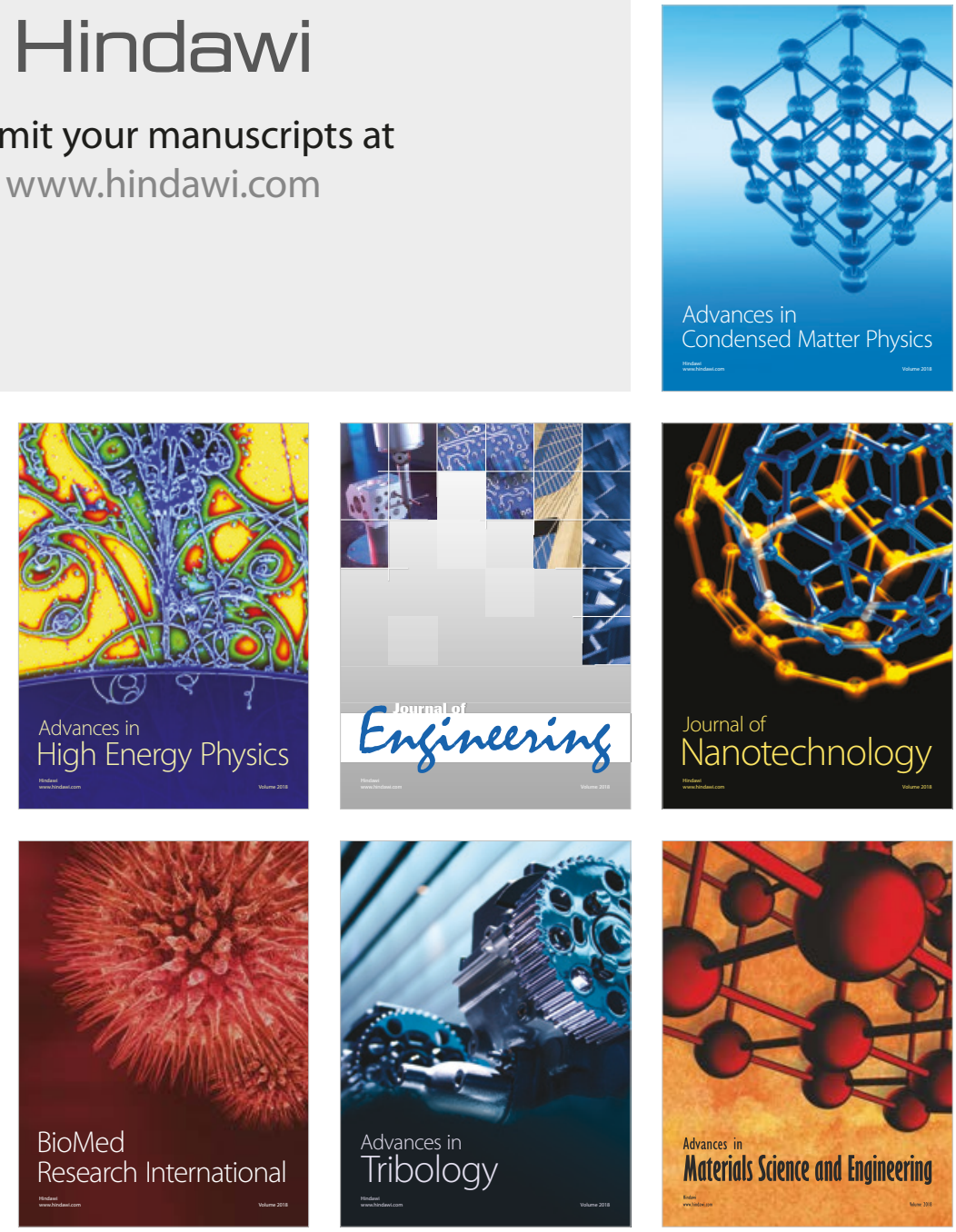